Thorax (1950), 5, 40.

\title{
OESOPHAGEAL SENSATION AFTER SYMPATHECTOMY
}

BY

\author{
A. F. WILLIAMS \\ Surgical Professorial Unit, Manchester Royal Infirmary
}

The removal of extensive portions of the sympathetic nervous system, an operation now frequently performed for hypertension, makes it possible to investigate what part this system plays in carrying sensation from different viscera. A study is presented here of the role of the sympathetic nervous system in the sensation of the oesophagus.

\section{Sympathetic Nerve Supply of THE Oesophagus}

At one time it was believed that the oesophagus received no sympathetic nerve supply (Knight, 1934, quoting Gaskell), but now all authorities consider that such a supply does exist. There is, however, much less agreement as to the nature of its distribution, but it has been shown that fibres reach the oesophagus from the inferior cervical and thoracic ganglia, the aortic plexus, and splanchnic nerves. There is uncertainty as to which is the most important source, Kuntz (1934), for instance, believing that the inferior cervical ganglia have the biggest share. Fibres from the thoracic ganglia are probably few in number (Woollard, 1935), while the splanchnic nerves are concerned in the supply of the lower oesophagus. It is clear, therefore, that to ensure complete interruption of the sympathetic supply to the oesophagus the stellate and thoracic ganglia must be put out of action.

\section{Method}

Sensation was tested by the distension of a balloon attached to a catheter and also to a sphygmomanometer to measure the pressure of the balloon as shown in

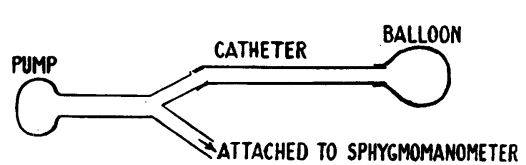

Fig. 1.-The apparatus used. Fig. 1.

The balloon was swallowed until it reached a distance of 16 in. $(40 \mathrm{~cm}$.) from the incisor teeth; it was then inflated and the patient's response noted. It was then deflated, withdrawn one inch, and sensation again tested, the procedure being repeated six to eight times. Patients were generally able to indicate the approximate position of the balloon, which when inflated they compared to a bolus of food arrested on its way to the stomach. The pain was referred to the midline anteriorly and to a much less extent posteriorly. A higher pressure was required in the lower than the middle oesophagus before any sensation was felt.

\section{EXPERIMENTAL Findings}

Series 1.- In the first set of experiments the effect of a bilateral removal of the ganglia from D4 to L3 inclusive and of the three splanchnic nerves was investigated. 
The extent of the sympathectomy was confirmed by measuring changes in the electrical resistance of the skin.

Eleven patients were examined, two being normal individuals, two having had only a unilateral operation, and one being examined after one side had been completed as well as after both sides. The tests were performed two to three weeks after an operation.

Before operation pain was noted at the lower end of the oesophagus at pressures from $40-60 \mathrm{~mm}$. $\mathrm{Hg}$, Hurst (1911) also finding that pain was caused at pressures of 44-54 mm. Hg. In the three patients upon whom a unilateral operation had been performed pain was noticed at pressures of 30,40 , and $50 \mathrm{~mm}$. $\mathrm{Hg}$ respectively, and was exactly in the middle as in the previous examination. The seven patients upon whom bilateral operations had been performed all felt pain at pressures of $40-80$ $\mathrm{mm}$. $\mathrm{Hg}$, being virtually the same as before operation, and the pain was again referred to the midline. As before operation the lower oesophagus was found to be less sensitive than the middle and upper segments.

Table I gives the findings from a patient before operation, and they are typical of both pre- and post-operative findings.

TABLE I

Pressures at which Pain was felt at Varying Oesophageal levels in a Typical Patient

\begin{tabular}{c|c}
\hline Distance of Balloon from Incisor Teeth (in.) & Pressure at which Pain was Felt (mm. Hg) \\
\cline { 2 - 2 } & 60 \\
16 & 50 \\
14 & 40 \\
13 & 50 \\
12 & 40 \\
11 & 30 \\
10 & 30 \\
8 & 20 \\
& 15 \\
\hline
\end{tabular}

Series 2.-Although the operations described above had removed the greater part of the sympathetic system it was still possible for fibres to arise from the ganglia of D1, 2, and 3 and supply the oesophagus. Sensation was therefore tested in five other patients in whom these ganglia had been put out of action by bilateral cervico-dorsal ganglionectomy or novocaine infiltration. Novocaine blocks were considered successful if the patient had a bilateral Horner's syndrome and warm, dry hands. The results were exactly as before, patients feeling pain at pressures from $30-60 \mathrm{~mm}$. $\mathrm{Hg}$.

The separate interruption of the upper and lower portions of the sympathetic system did not alter the ability of the patient to recognize distension of the oesophagus. In one patient it was possible to do the test after the whole of the sympathetic system had been eliminated. In this patient the ganglia up to D4 inclusive on both sides had been removed; the ganglia D1, 2, and 3 on both sides were blocked by novocaine, but even then there was no change in sensation produced by distending the oesophagus, though presumably there were no sympathetic fibres by which sensation could be conducted from the oesophagus. 


\section{Discussion}

These experiments show that the oesophagus depends upon the sympathetic system for sensation to a very slight extent, if at all. It was not possible to detect any change in its ability to recognize distension after varying parts of the sympathetic system had been eliminated and in the one patient in whom apparently the whole of this system had been interrupted.

From these investigations it cannot certainly be said whether sensation after sympathetic denervation was perceived in the oesophagus or in adjacent structurese.g., the mediastinal parietal pleura - or whether the sensory fibres run in the vagi or somatic nerves. Hurst (1911) believed that they ran in the vagi from the observation that a patient suffering from bulbar paralysis did not appear to possess oesophageal sensation when tested by balloon distension. Whether sensation remains in the oesophagus itself or in its immediate relations, it is evident that attacks upon the sympathetic system alone are likely to be of no avail if employed for the relief of pain in such lesions as, for example, irresectable carcinoma of the oesophagus.

\section{SUMMARY}

The effects of sympathectomy on sensation produced by distending the oesophagus have been studied. The sympathetic system appears to play no part in the sensation felt when the oesophagus is distended.

I wish to thank Professor A. M. Boyd for his help and advice, and Dr. J. H. Kellgren for his criticism of this paper. I also wish to thank Dr. A. H. Ratcliffe for testing the electrical resistance of the skin in the patients.

REFERENCES

Hurst, A. F. (1911). Lancet, 1, 1051.

Knight, G. C. (1934). Brit. J. Surg., 22, 155.

Kuntz, A. (1934). The Autonomic Nervous System. London.

Woollard, H. H. (1935). Brit. J. Surg., 23, 425. 